\title{
UTILIZAÇÃO DE SISTEMAS SOLARES PARA MINI E MICROGERAÇÃO NA BAHIA
}

\author{
Barbara Gomes Pereira; Joyce Mara Brito Maia²; Fábio André Lora² \\ 1 Universidade Federal do Recôncavo da Bahia - UFRB, Centro de Ciência e \\ Tecnologia e Sustentabilidade em Energia e Sustentabilidade - CETENS; Feira de \\ Santana/BA; barbarapereira501@gmail.com \\ 2 Universidade Federal do Recôncavo da Bahia - UFRB, Centro de Ciência e \\ Tecnologia e Sustentabilidade em Energia e Sustentabilidade - CETENS; Feira de \\ Santana/BA
}

Resumo: Recurso abundante, a energia solar tem como formas de aproveitamento mais utilizadas a geração de energia elétrica e o aquecimento solar, nesse contexto, o objetivo deste trabalho é apresentar um estudo sobre a utilização de sistemas híbridos térmicos elétricos para mini e microgeração no estado da Bahia. Foram coletados dados do potencial de irradiação solar em oito cidades da Bahia, em especial Feira de Santana, e analisadas a capacidade de geração de energia elétrica e de aquecimento via e energia solar. Neste artigo é possível verificar os benefícios da micro e minigeração descentralizada em comunidades rurais e indústrias, além da possibilidade de utilização das tecnologias solares híbridas.

Palavras-Chave: Radiação solar; sistemas híbridos; micro geração de energia.

\section{USE OF SOLI MINI AND MICROGENERATION SYSTEMS IN BAHIA}

\begin{abstract}
Abundant resource, solar energy has as its most used forms of use the generation of electricity and solar heating, in this context, the objective of this paper is to present a study on the use of electric hybrid thermal systems for mini and microgeneration in the state of Bahia. Data were collected on the potential of solar radiation in eight cities of Bahia, especially Feira de Santana, and analyzed the ability to generate electricity and heating via and solar energy. In this paper it is possible to verify the benefits of decentralized micro and minigeneration in rural communities and industries, besides the possibility of using hybrid solar technologies.
\end{abstract}

Keywords: Solar radiation; hybrid systems; micro energy generation. 


\section{INTRODUÇÃO}

A Bahia é um estado brasileiro que detém uma extensão territorial de $564.722,611 \mathrm{~km}^{2}$. O estado possui um dos melhores potenciais de produção de energia solar do país, o potencial estimado supera o consumo atual de energia elétrica do estado que em 2015 era de 28,1TWh[1].

Apesar do crescimento da utilização das renováveis nos últimos anos, a maior parte da energia utilizada na Bahia vem das hidrelétricas, ela é responsável por $59,6 \%$ da energia fornecida. Essa alta predominância de uma fonte torna o sistema elétrico do estado dependente e fragilizado diante da sazonalidade deste recurso, tornandose necessário recorrer ao uso das termelétricas, um recurso que utiliza em sua grande maioria combustíveis fósseis e tem um alto custo de operação agregado. As termelétricas são responsáveis por aproximadamente $22,3 \%$ do fornecimento elétrico baiano [2].

Empreendimentos que utilizam como fonte a energia solar, como a instalação da usina solar no estádio de Pituaçu em Salvador, Figura 1, tem-se espalhado por todo o estado. Contudo, verifica-se uma maior exploração deste recurso no interior do estado. Atualmente temos um dos maiores parques solares do país na cidade de Bom Jesus da Lapa, o parque é a junção de duas usinas, Bom Jesus da Lapa, com 80 MW (megawatts) e Lapa, com $78 \mathrm{MW}$, totalizando $158 \mathrm{MW}$ de potência. Em um ano, o parque solar Lapa é capaz de gerar 340 GWh (gigawatts-hora) de energia, suficientes para abastecer 166 mil casas nesse período [3].

Figura 1 - Usina solar do estádio de Pituaçu

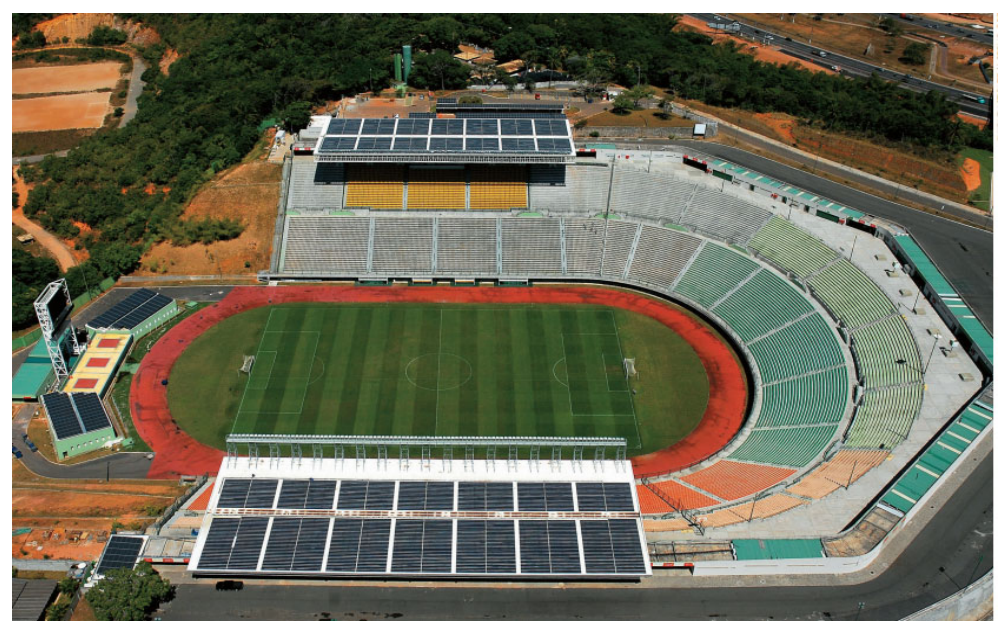

Fonte: Atlas solar da Bahia [1]

A instalação destas e de outras usinas na região são estratégicas, pois se beneficiam do grande potencial de irradiação disponível, que favorece a utilização de sistemas térmicos e elétricos movidos a energia solar. Assim, a energia solar desponta como uma das fontes mais indicadas para a micro e minigeração, de forma a atender as demandas domésticas e industriais de energia na Bahia [4]. 
Dessa forma, o objetivo deste trabalho é apresentar uma revisão bibliográfica sobre a utilização de sistemas térmicos elétricos para a microgeração e minigeração no estado da Bahia. Mostrando como estes sistemas, se utilizados em conjunto, podem alcançar maiores níveis de eficiência, reduzindo os custos e as perdas relacionadas, e promovendo a utilização do potencial disponível na Bahia.

\section{METODOLOGIA}

Este trabalho tem como alvo a explicação ou análise de um aspecto ou problema a partir de referências teóricas já publicadas. Utilizou-se neste trabalho referências que auxiliassem na busca de conhecimentos sobre a utilização de sistemas térmicos solares correlacionando-os com a questão da micro e minigeração de energia no estado da Bahia.

\subsection{A radiação solar na Bahia}

A radiação solar pode ser definida como a propagação de ondas eletromagnéticas, ela é responsável pela maior parte da energia presente na Terra [4]. A energia emitida em um único dia de radiação que atinge o planeta é consideravelmente maior que toda a energia consumida nele em um ano [5].

A irradiação é a taxa na qual todas as radiações incidem sobre uma superfície a partir da sua vizinhança [6]. A irradiação global horizontal é uma componente que permite avaliar o nível de produção de uma célula fotovoltaica. Para a analisar o potencial de produção em um projeto solar são necessários ter em mãos dados sobre a incidência de radiação da região, que depende de quatro critérios básicos: latitude, altitude, nebulosidade e inclinação [1].

A Bahia dentro destes critérios apresenta muitas vantagens, ela está localizada em baixas latitudes, o que reduz a variação de duração dos dias, ela possui regiões que que estão a altos níveis de altitude, e até a nebulosidade, um fator muitas vezes negativo, ajuda a região, pois o céu no interior do estado durante o inverno é mais limpo favorecendo a incidência de radiação.

\subsection{A utilização da radiação solar como fonte de energia}

As fontes renováveis tem ganhado especial relevância no fornecimento e geração de energia em pequena escala. Além de conseguirem se instalarem mais próximos dos consumidores finais, elas geram impactos ambientais ínfimos [6], quando comparadas aos combustíveis fósseis. As duas formas de aproveitamento da energia solar mais utilizadas são a geração de energia elétrica e o aquecimento solar [5]. A tecnologia fotovoltaica é a forma de aproveitamento solar mais disseminada atualmente [1]. Eles são instalações que captam a radiação solar e a transformam em 
energia elétrica utilizando semicondutores fotossensíveis que geram uma diferença de potencial terminais da junção P-N2 promovendo o aparecimento de uma corrente contínua. As tecnologias fotovoltaicas mais comuns são as de silício mono e policristalino, silício amorfo e filmes finos [7].

Um coletor solar Figura 2, eles substituem o consumo elétrico dos chuveiros, grandes responsáveis pelos custos nas contas de energia elétrica [6]. Aproximadamente 20 bilhões de kWh de eletricidade são consumidos no Brasil para este uso [8]. Uma vantagem dos coletores solares é que eles podem ser utilizados mesmo estando em lugares onde o clima e as condições de radiações são baixas [9].

Figura 2 - Coletor Solar térmico

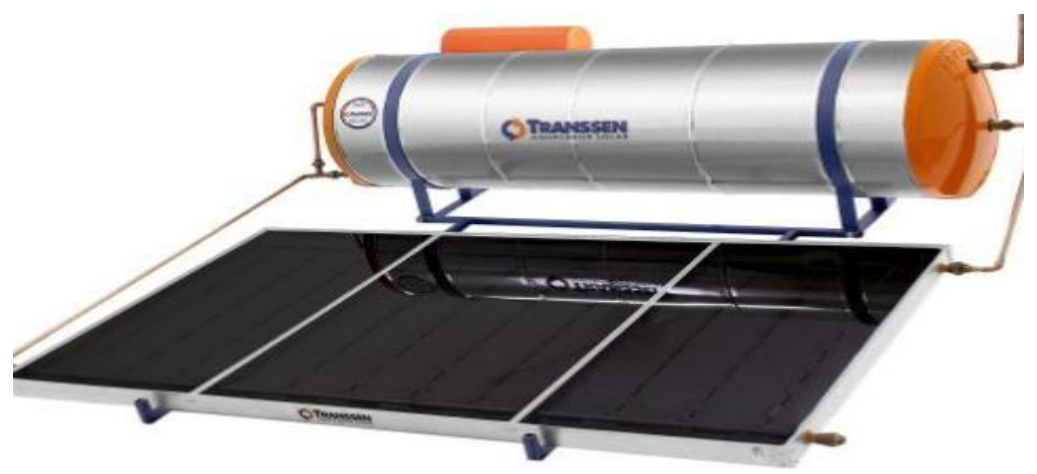

Fonte: Painéis Solares (2018).

A energia solar térmica utiliza como princípio de obtenção de energia o calor gerado pela radiação eletromagnética num coletor solar onde dentro há circulação de um fluido, o coletor solar funciona como trocador de calor, transferindo a energia absorvida para o fluido [9]. No entanto essas duas formas de utilização da energia solar também podem ser encontradas em um mesmo equipamento. Eles são chamados de painéis ou coletores híbridos porque incorporam duas funções num mesmo equipamento [8-9].

Figura 3 - Sistema híbrido fotovoltaico e térmico.

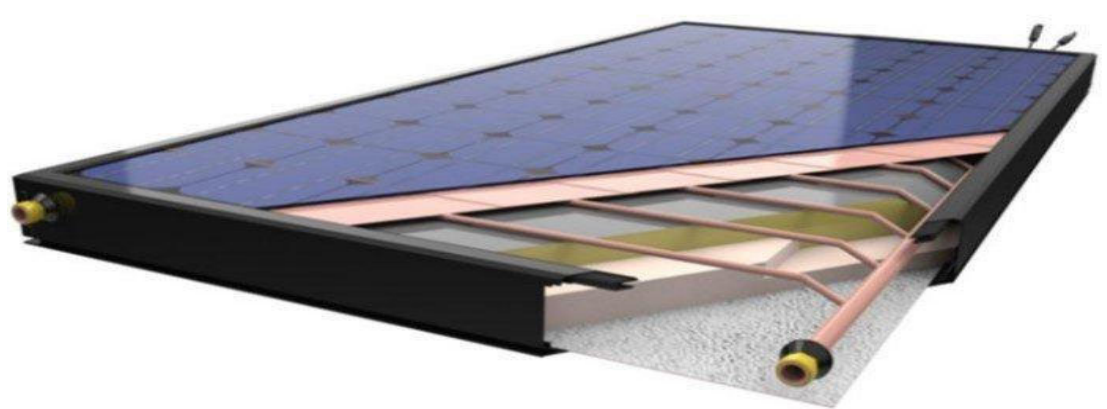

Fonte: Portal Energia (2018). 
Um dos problemas mais encontrados que favorecem a utilização desse tipo de sistemas é a dissipação de energia para o ambiente. Num sistema fotovoltaico menos de $20 \%$ da energia é convertida em eletricidade, todo o restante é revertido em calor. Essa energia que antes era desperdiçada pode vir a ser utilizada. Neste processo o fluxo de água no painel irá diminuir sua temperatura e manter sua eficiência, ao mesmo tempo que a energia dissipada pelo painel fotovoltaico irá aquecer a água [9].

\subsection{Micro e mini geração na Bahia}

A geração distribuída, pode ser definida como a geração de energia próxima aos consumidores com a inserção de excedentes na rede [10]. Ela torna o consumidor independente e concede benefícios econômicos aos consumidores, devido ao sistema de compensação de créditos, que permite a unidade geradora de trocar créditos com a concessionária.

A Bahia tem um potencial de utilização de renováveis para a geração distribuída bastante alto, entretanto não se percebe políticas estaduais que impulsionem este setor. Na Tabela 1 estão os dados de irradiação de oito diferentes cidades baianas, as quais que apresentam características e economias distintas, mas que são de extrema importância no estado.

Tabela 1. Irradiação solar diária média

\begin{tabular}{|c|c|c|c|}
\hline Cidade & $\begin{array}{l}\text { Menor índice/mês } \\
\left(\mathbf{k W h} / \mathrm{m}^{2} . \text { dia) }\right.\end{array}$ & $\begin{array}{l}\text { Maior índice/mês } \\
\text { (kWh/m².dia) }\end{array}$ & $\begin{array}{l}\text { Média Anual } \\
\text { (kWh/m².dia) }\end{array}$ \\
\hline Paulo Afonso & 4,01/Jun & $6,49 / \mathrm{Nov}$ & 5,46 \\
\hline Salvador & $3,75 /$ Jun & 6,39/Dez & 5,25 \\
\hline Camaçari & $3,78 /$ Jun & 6,37/Dez & 5,21 \\
\hline Feira de Santana & $3,61 /$ Jun & $6,01 / \mathrm{Dez}$ & 5,01 \\
\hline Lençóis & $3,80 /$ Jun & 5,92/Fev & 5,04 \\
\hline $\begin{array}{l}\text { Luís Eduardo } \\
\text { Magalhães }\end{array}$ & $5,09 /$ Jun & $6,18 /$ Set & 5,62 \\
\hline $\begin{array}{c}\text { Bom Jesus da } \\
\text { Lapa }\end{array}$ & $4,88 /$ Jun & $6,62 / \mathrm{Jan}$ & 5,88 \\
\hline Porto Seguro & $3,57 /$ Jun & $6,29 / \mathrm{Fev}$ & 5,02 \\
\hline
\end{tabular}

Fonte: Potencial Solar - SunData v 3.0 - (cresesb 2017). 
Na tabela acima é possível identificar que o potencial médio baiano durante do ano de 2017 apresenta-se bastante interessante nas 8 cidades, contudo cidades localizadas no oeste, região que apresenta um perfil de cidades com economia baseado no agronegócio, conseguem atingir potenciais de radiação nos períodos de Junho bem próximos da média anual.

Todavia, não se pode negar que a micro e mini geração solar também beneficia o setor industrial e comercial baiano. As cidades de Feira de Santana e Camaçari se encaixam perfeitamente nestas categorias por apresentarem, respectivamente, os maiores polos comerciais e indústrias da Bahia. Apesar de não apresentarem números tão elevados de radiação, as cidades estão dentro da média apresentada pelas outras cidades anualmente.

Ambos setores consomem muita energia, o setor industrial por sua vez é o setor com maior consumo energético no Brasil, tendo o calor como uma necessidade em diversos atividades e sendo os custos elétricos responsáveis pelo maiores gastos financeiros destas indústrias [5]. Existem diversas perspectivas positivas para 0 avanço da micro e mini geração distribuída nestes setores [11]:

- Para atender a demanda desses setores é necessário um número maior de painéis e ou coletores solares em relação a utilização residencial, o que significa diminuição no custo destas tecnologias, aumento da sua utilização também estimula o setor de vendas e instalações de painéis e coletores solares, bem como fomentam a busca por capacitação e a geração de novos empregos;

- Ela também promove a diminuição de utilização das outras fontes fosseis, diversificando e promovendo segurança energética na matriz elétrica do estado;

- Por fim a micro e mini geração também funcionam como um fator de competitividade para estas empresas, devido os clientes buscarem cada vez mais por empresas que estejam baseadas em processos mais sustentáveis.

\section{DISCUSSÃO DE POSSIBILIDADES}

Um dos maiores impasses para os avanços da utilização da radiação solar como fonte de energia é o desenvolvimento de tecnologias que consigam realizar o aproveitamento máximo do potencial disponível, pois esse tipo de obtenção ainda tem muitas perdas associadas.

Conforme verificado, a utilização da energia solar pode agrupar benefícios sociais, econômicos e ambientais a partir da aplicação deste recurso para geração própria energia. A Bahia apresenta um alto potencial de irradiação, sobretudo no oeste do estado, e ainda possui grandes jazidas de silício, material de suma importância para a fabricação de painéis fotovoltaicos, fatores que aliados favorecem 0 desenvolvimento e utilização das formas mais comuns de conversão de energia solar. 
No entanto, o estado ainda possui pouca capacidade instalada de sistemas de mini e microgeração, este processo se dá em virtude dos custos do equipamento, do projetos e da falta de incentivos estaduais que tornam esse investimento caro e inviável para pequenos sistemas. Tornando-se necessário maiores incentivos governamentais para que a micro e minigeração distribuída desenvolva um papel de geração eficiente de energia e, consequentemente, sejam capazes de atenuar à dependência dos combustíveis fósseis.

\section{Agradecimentos}

Destinam-se os agradecimentos ao Conselho Nacional de Desenvolvimento Cientifico e Tecnológico -CNPq pelo fomento do projeto e bolsas de iniciação científica.

\section{REFERÊNCIAS}

1 CIMATEC, Senai. Atlas Solar: Bahia. Salvador: Senai Cimatec, 2018. 76 p. Elaborado por AWS Truepower, Camargo Schubert Engenheiros Associados, FIEB/SENAI CIMATEC. Disponível em: <http://www.senaicimatec.com.br/download/Atlas-Solar-Bahia-2018.pdf>. Acesso em: 07 ago. 2019.

${ }^{2}$ OLIVEIRA, Thiago Figueiredo de et al. A matriz energética baiana e o potencial de aproveitamento solar e eólico na geração de energia elétrica no estado da Bahia. Revista Eletrônica de Gestão e Tecnologias Ambientais, [s.I.], v. 6, n. 1, p.1-17, 24 abr. 2018. Semestral.

${ }^{3}$ MARTINS, Jeovane Bet. ESTRATÉGIAS E MECANISMOS ECONÔMICOS PARA INSERÇÃO DE SISTEMAS FOTOVOLTAICOS DE GERAÇÃO DISTRIBUÍDA NA MATRIZ ELÉTRICA BRASILEIRA. 2018. 48 f. TCC (Graduação) - Curso de Engenharia de Energia, Universidade Federal de Santa Catarina, Araranguá, 2018.

${ }^{4}$ KANNAN, Nadarajah; VAKEESAN, Divagar. Solar energy for future world: - A review. Renewable and Sustainable Energy Reviews, [s.I.], v. 62, p.1092-1105, set. 2016. Monthly. Elsevier BV. http://dx.doi.org/10.1016/j.rser.2016.05.022.

${ }^{5}$ LENZ, Anderson Miguel. Uso da energia solar para aquecimento de água e microgeração de eletricidade visando a sustentabilidade energética de uma residência unifamiliar rural. 2016. $91 \mathrm{f}$. Tese (Doutorado) - Curso de Engenharia de Energia na Agricultura, Universidade Estadual do Oeste do Paraná, Cascavel, 2016. 
${ }^{6}$ INCROPERA, F. P.; DE WITT, D. P.; BERGMAN, T. Fundamentos de transferência de calor e massa. 6. ed. Rio de Janeiro: LTC, 2008. 643

7 EMPRESA DE PESQUISA ENERGÉTICA - EPE. Anuário Estatístico de Energia Elétrica, 2015. Disponível em: http://www.epe.gov.br/AnuarioEstatisticodeEnergiaEle Acesso em: 08 ago. 2019.

8 MAKKI, Adham; OMER, Siddig; SABIR, Hisham. Advancements in hybrid photovoltaic systems for enhanced solar cells performance. Renewable And Sustainable Energy Reviews, [s.l.], v. 41, p.658-684, jan. 2015. Monthly. Elsevier BV. http://dx.doi.org/10.1016/j.rser.2014.08.069.

${ }^{9}$ RIBEIRO, Nadja Cardoso Campos. Análise de sistema híbrido solar: Fotovoltaico e térmico. 2016. 39 f. TCC (Graduação) - Curso de Engenharia de Energia, Universidade de Brasília, Brasília, 2016. Universidade Federal da Bahia. http://dx.doi.org/10.9771/gesta.v6i1.21711.

10 ALSTONE, Peter; GERSHENSON, Dimitry; KAMMEN, Daniel M.. Decentralized energy systems for clean electricity access. Nature Climate Change, [s.I.], v. 5, n. 4, p.305-314, 25 mar. 2015. Week. Springer Science and Business Media LLC. http://dx.doi.org/10.1038/nclimate2512.

11 VIDAL, Adriana Lopes. Energia Solar no Brasil: Geração distribuída nos setores comercial e industrial. 2017. 57 f. TCC (Graduação) - Curso de Economia, Universidade Federal do Rio de Janeiro, Rio 